\title{
Ground surface temperature reconstruction for the last 500 years obtained from permafrost temperatures observed in the SHARE STELVIO Borehole, Italian Alps
}

\author{
Mauro Guglielmin $^{1}$, Marco Donatelli ${ }^{2}$, Matteo Semplice ${ }^{3}$, and Stefano Serra Capizzano ${ }^{2,4}$ \\ ${ }^{1}$ Department of Theoretical and Applied Sciences, Insubria University, Via Dunant 3, 21100 Varese, Italy \\ ${ }^{2}$ Department of Science and High Technology, Insubria University, Como, Italy \\ ${ }^{3}$ Dipartimento di Matematica, Università di Torino, Torino, Italy \\ ${ }^{4}$ Department of Information Technology, Uppsala University, Uppsala, Sweden
}

Correspondence: Mauro Guglielmin (mauro.guglielmin@ uninsubria.it)

Received: 23 February 2017 - Discussion started: 2 March 2017

Revised: 12 February 2018 - Accepted: 1 May 2018 - Published: 6 June 2018

\begin{abstract}
Here we present the results of the inversion of a multi-annual temperature profile $(2013,2014,2015)$ of the deepest borehole $(235 \mathrm{~m})$ in the mountain permafrost of the world located close to Stelvio Pass in the Central Italian Alps. The SHARE STELVIO Borehole (SSB) has been monitored since 2010 with 13 thermistors placed at different depths between 20 and $235 \mathrm{~m}$. The negligible porosity of the rock (dolostone, $<5 \%$ ) allows us to assume the latent heat effects are also negligible. The inversion model proposed here is based on the Tikhonov regularization applied to a discretized heat equation, accompanied by a novel regularizing penalty operator. The general pattern of ground surface temperatures (GSTs) reconstructed from SSB for the last 500 years is similar to the mean annual air temperature (MAAT) reconstructions for the European Alps. The main difference with respect to MAAT reconstructions relates to post Little Ice Age (LIA) events. Between 1940 and 1989, SSB data indicate a cooling of ca. $1{ }^{\circ} \mathrm{C}$. Subsequently, a rapid and abrupt GST warming (more than $0.8^{\circ} \mathrm{C}$ per decade) was recorded between 1990 and 2011. This warming is of the same magnitude as the increase in MAAT between 1990 and 2000 recorded in central Europe and roughly doubling the increase in MAAT in the Alps.
\end{abstract}

\section{Introduction}

The thermal regime of the uppermost ground is determined by the geothermal heat flow and by the fluctuations of temperature at the surface. If rock was homogeneous and no temperature change were to occur at the surface, the temperature would increase linearly with depth, unless spontaneous heat production is present in the vicinity of the well. The gradient of this temperature increase would be governed solely by the magnitude of the terrestrial heat flow and by the thermal conductivity of the rock. However, variations in ground surface temperature (GST) propagate downwards into the rock as attenuating thermal waves, superimposed on the aforementioned linear temperature profile. The depth to which disturbances can be recorded is determined mainly by the amplitude and duration of the temperature change at the surface. Generally, propagation of climate signals is slow and it can take more than 1000 years to reach the depth of $500 \mathrm{~m}$ (Huang et al., 2000). For a better conservation of the climate signal in the thermal profile, no lateral heat advection (due for example to ground water flow) should be present (Lewis and Wang, 1992). Since normally no groundwater circulation is present within continuous permafrost in the polar areas but also in rocky areas within mountain permafrost, boreholes drilled in these areas are particularly suited for GST reconstructions.

Lachenbruch and Marshall (1986) were among the first to demonstrate that thermal profiles obtained from boreholes drilled in permafrost can be used to reconstruct GST changes. 
These do not require calibration because the heat conduction equation is directly used to infer temperature changes at the ground surface. Today, the majority of permafrost boreholes used to reconstruct GSTs are located in the polar regions of North America and Eurasia where the boreholes can be drilled on flat terrain, with negligible topographical effects, and with permafrost thicknesses typically exceeding $100 \mathrm{~m}$, thereby providing deep temperature logs and long GST reconstructions. Conversely, several factors like porosity, water/ice and latent heat flows can significantly influence the thermal properties and the thermal signal especially measured in frozen sediment boreholes, discussed in Mottaghy and Rath (2006) as well.

The Share Stelvio Borehole (SSB) in the Italian Alps is the deepest drilled within permafrost in the mid-latitude mountains of Europe. Because the permafrost thickness exceeds $200 \mathrm{~m}$ at this site it allows reconstruction of GST for some centuries and much more than in the other mountain permafrost boreholes. In addition, the Stelvio borehole is located on a rounded summit with gentle side slopes. Therefore, site-specific topographic influences are largely eliminated. As such, it is different from the other boreholes drilled in permafrost in the Alps (e.g. PACE boreholes at Schilthorn or Stockhorn; see Harris et al., 2003; Gruber et al., 2004; Hilbich et al., 2008).

Recent atmospheric warming (over the last century) in the European Alps has been roughly twice the global average (Böhm et al., 2001; Auer et al., 2007). Despite its high sensitivity, no GST reconstruction based on borehole thermal profiles is available for this part of the world. Instead, reconstructions of summer air temperatures have been based on either tree rings (e.g. Büntgen et al., 2006; Corona et al., 2010) or lake sediments (e.g. Larocque-Tobler et al., 2010; Trachsel et al., 2010) for the last 500-1000 years, or both (Trachsel et al., 2012). With rare exceptions (e.g. ice cores; Barbante et al., 2004), the other proxy data are from sites at elevations that rarely exceed $2000 \mathrm{~m}$ a.s.l. and all the other monitored permafrost boreholes in Europe do not exceed $100 \mathrm{~m}$ of depth (see Harris et al., 2003). However, several papers describe GST reconstructions for the last 500-1000 years using borehole data at hemispheric or global scales (e.g. Huang et al., 2000; Beltrami and Bourlon, 2004).

The SSB data provide GST history from a high elevation site ( $3000 \mathrm{~m}$ a.s.1.). Such locations are important because snow cover can significantly affect the GST (Zhang, 2005; Ling and Zhang, 2006; Cook et al., 2008). They are also relevant with respect to glacier dynamics and their feedbacks with the global atmospheric system (IPCC, 2013).

This paper reconstructs the GSTs inferred from this borehole and compares the results with existing multi-proxy reconstructions for the European Alps and elsewhere.
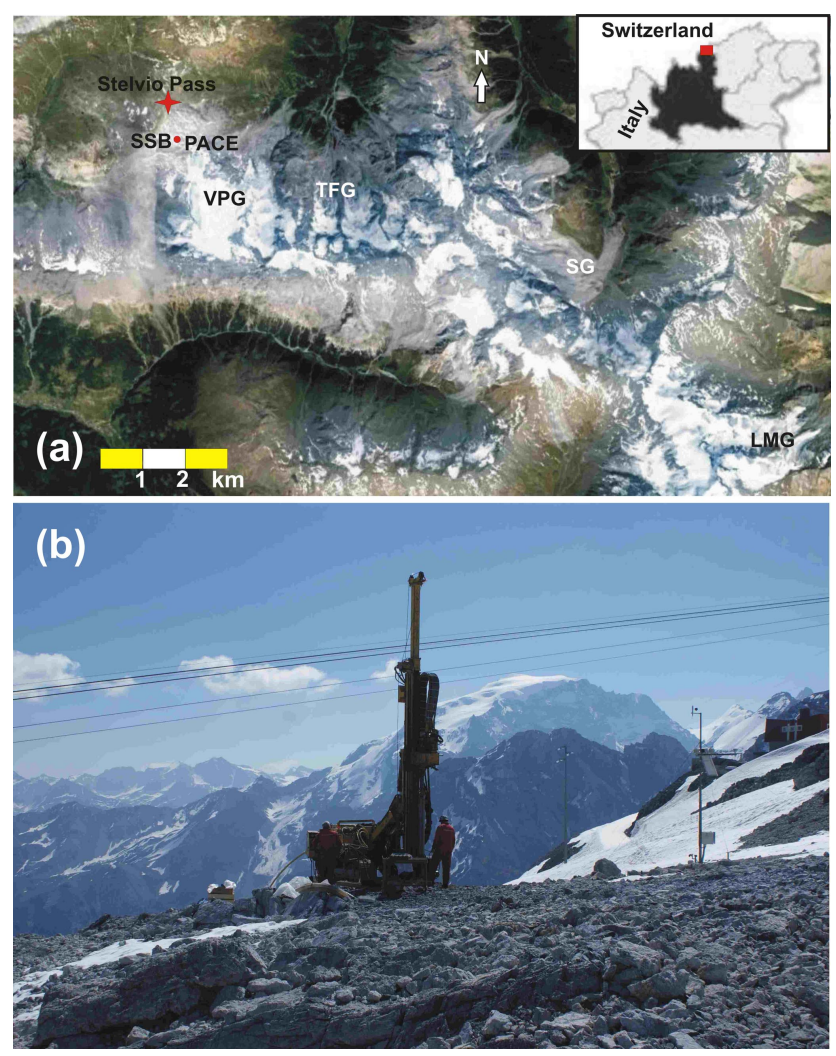

Figure 1. Study area: (a) location of the study area with the surrounding glaciers and the reconstructed glacier limits of the area (VPG: Vedretta Piana glacier; TFG: Trafoi glacier; SG: Solda glacier; LMG: La Mare glacier; PACE: PACE Borehole; SSB: Share Stelvio Borehole); (b) view of the drilling equipment during the realization of the SSB in summer 2009.

\section{Study area}

The Stelvio-Livrio area is a summer ski location, located between the Stelvio Pass ( $2758 \mathrm{~m}$ a.s.l.) and Mt Livrio (3174 m a.s.1.), within the Stelvio National Park. The area is characterized by bedrock outcrops (mainly dolostone), apart from some Holocene moraines (Fig. 1a). The SSB was drilled in 2009 and is only $10 \mathrm{~m}$ from the PACE borehole, drilled in $1998\left(46^{\circ} 30^{\prime} 59^{\prime \prime} \mathrm{N}\right.$; $10^{\circ} 28^{\prime} 35^{\prime \prime} \mathrm{E}, 3000 \mathrm{~m}$ a.s.l.; Fig. 1b). Both boreholes are located on a flat barren summit surface oriented NNW-SSE. The side slopes (SSW and NNE exposed) are gentle, with the northern slope being only slightly steeper ( 14.1 vs. $12.5^{\circ}$ vs. from the top down to $2900 \mathrm{~m}$ a.s.l.; Fig. 2, solid line). Despite their lithological homogeneity and their low porosity $(<5 \%$, Fabrizio Berra, personal communication, 2017), the two boreholes differ because in the PACE borehole two fractures filled by ice were encountered at 42 and $90 \mathrm{~m}$ depth (Guglielmin et al., 2001) but no evidence of ice was observed during the SSB drilling. Using PACE temperature profile and typical thermal conductivity and heat flow values cited in literature $\left(4.0 \mathrm{~W} \mathrm{~m}^{-1} \mathrm{~K}^{-1}\right.$, 

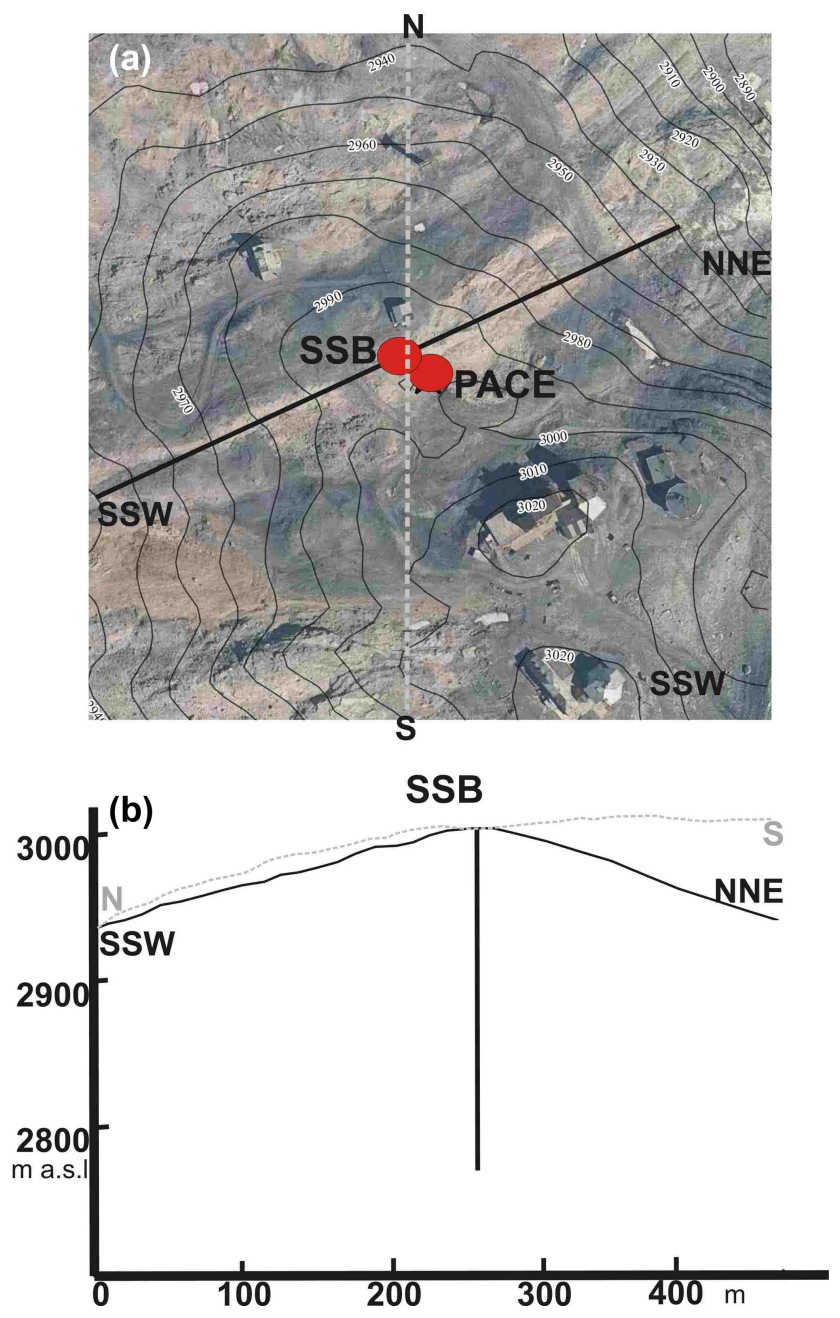

Figure 2. Topography of the SSB site: (a) digital elevation model (5 $\mathrm{m}$ resolution) of the SSB site and (b) SSW-NNE (solid line) and $\mathrm{N}-\mathrm{S}$ (dashed line) transects through the Stelvio summit. Horizontal and vertical scales as well as thermistor chain position and depths are plotted to the same scale.

Clauser and Huenges, $1995 ; 85 \mathrm{~mW} \mathrm{~m}^{-2}$, Cermak et al., 1992), permafrost thickness in the SSB was estimated to be around $220 \mathrm{~m}$.

\section{Methods}

\subsection{Field data}

The SSB was drilled in early July 2010, using refrigerated compressed-air-flush drilling technology. The stratigraphy was obtained using analyses of the cuttings (sampled every $10 \mathrm{~m}$ ) and, for the first $100 \mathrm{~m}$, through analysis of video logging. Since September 2010, the thermal regime of the SSB was monitored with thermometers placed according to the PACE protocol (Harris et al., 2001). The accuracy of the thermometers is $0.1{ }^{\circ} \mathrm{C}$ and the resolution is $0.01{ }^{\circ} \mathrm{C}$. The ther- mistors recorded the daily ground temperature (minimum, maximum and average) at 20, 25, 35, 40, 60, 85, 105, 125, $145,165,205,215$ and $235 \mathrm{~m}$ of depth. Since 1998, the main climatic parameters at the site (air temperature, snow cover, incoming radiation) have been monitored. Below the $20 \mathrm{~m}$ depth, no significant seasonal variations in temperature are recorded.

\subsection{Laboratory data}

The thermal properties of the three main facies observed in the stratigraphy were measured in the laboratory at three different temperatures $\left(0,-1,-3^{\circ} \mathrm{C}\right)$. Thermal diffusivity and specific heat were measured by NETZSCH-Gerätebau GmbH (Selb, Germany) using a NETZSCH model $457 \mathrm{Mi}-$ croFlashTM laser flash diffusivity apparatus. Thermal diffusivity measurements were conducted in a dynamic helium atmosphere at a flow rate of ca. $100 \mathrm{~mL} \mathrm{~min}^{-1}$ between -3 and $0^{\circ} \mathrm{C}$. Specific heat capacity was measured using the ratio method of ASTM E1461 (ASTM, 2003) with an accuracy of more than $5 \%$. Density of the rock at room temperature was determined using the buoyancy flotation method with an accuracy of better than $5 \%$. Thermal conductivity was calculated following Carlsaw and Jaeger (1959):

$\lambda=\rho \cdot c_{\mathrm{p}} \cdot \kappa$,

where $\lambda$ is the thermal conductivity $\left(\mathrm{W} \mathrm{m}^{-1} \mathrm{~K}^{-1}\right), \rho$ is the bulk density $\left(\mathrm{g} \mathrm{cm}^{-3}\right), c_{\mathrm{p}}$ is the specific heat capacity $\left(\mathrm{Jg}^{-1} \mathrm{~K}^{-1}\right)$, and $\kappa$ is the thermal diffusivity $\left(\mathrm{m}^{2} \mathrm{~s}^{-1}\right)$.

\subsection{Theory}

The temperature anomaly in the borehole at time $t$ at depth $z$ is modelled by the solution of the heat equation

$\frac{\partial A}{\partial t}-\frac{\partial}{\partial z}\left(\kappa \frac{\partial A}{\partial z}\right)=0$

for the domain $(t, z) \in\left(-t_{\max }, 0\right) \times\left(0, z_{\max }\right)$. Note that Eq. (1) can be derived from the classical formulation of Carlsaw and Jaeger (1959) under the hypothesis that the density and the specific heat capacity are constant with respect to the depth $z$ (see also Liu and Zhang, 2014), which is a good approximation for the SSB (see Sect. 4.1 and Appendix). Further, we have indicated with the earliest time $t_{\max }$, for which we will reconstruct the GST and with the depth of the borehole $z_{\max }$. Equation (1) can be solved to compute the temperature anomaly at any given past time $t$ and depth $z$ from the boundary values $A(t ; 0)$, which represent the GST history. If the GST data $A(t, 0)$ are piecewise constant, the solution of the direct problem for Eq. (1) can be found explicitly (see Carlsaw and Jaeger, 1959). In our case, we need to solve the inverse problem of finding the GST from the borehole data, which provide the anomaly measured at present $(t=0)$ or past times $(t>0)$ at some depth $z$ in the borehole. 


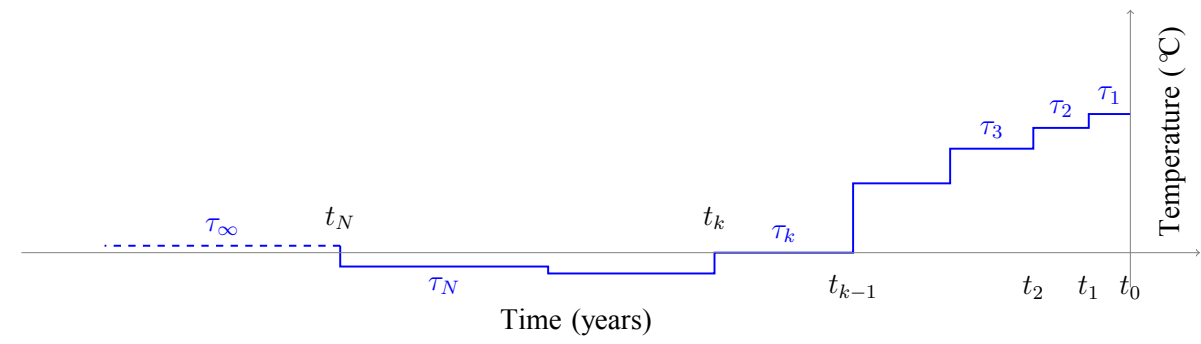

Figure 3. Example of a GST history parametrized by Eq. (2).

In order to exploit the abovementioned explicit solution, it is customary to approximate the GST with a piecewise constant function (see Fig. 3):

$\operatorname{GST}(t)=\left\{\begin{array}{ll}\tau_{k}, & t \in\left[-t_{k},-t_{k-1}\right], \\ \tau_{\infty}, & t<t_{N}\end{array}\right.$,

where $t_{k}$, for $k=1, \ldots, N$, is the sequence of times in the past at which we want to compute the value of the GST, and the $\tau_{k}$ 's are the unknown values to be computed. The diffusive nature of the heat equation has the effect that fine details of GST signals are averaged away as time progresses. Therefore, in the field data, one can find signals coming only from long-wavelength GST variations that occurred in the distant past, whereas short-wavelength signals are observable only if produced in the more recent history. In order to take into account long- and short-wavelength variations in GST for which each of them makes sense, contrary to the common use of choosing uniformly spaced time points, we choose

$t_{k}=(1+0.2 k)^{2}$

so that the reconstruction points are closer to each other in the recent past and more separated for distant ages. The choice of the parameter 0.2 is such that the reconstructed GST can contain signals of wavelength of at least 33 years from 1600 onwards, 23 years from 1800 onwards, 16 years from 1915 onwards and 9 years from 1985 onwards.

Once the sequence $t_{k}$ is chosen, the relation between the borehole temperature at depth $z_{j}$ predicted by the model and the unknown values $\tau_{k}$ of the GST anomaly is linear. When comparing the anomaly $A(z, t)$ described by the above equation with the measured data in the borehole, one has to take into account that measured data represent the superposition of the anomaly with a background signal (linearly increasing with depth) coming from the heat flow and past climatic changes since the Last Glacial Maximum as found for deeper boreholes by Safanda and Rajver (2001) or by Rath et al. (2012). This linear trend can be identified by linearly fitting the data from the deepest part of the borehole (below $60 \mathrm{~m}$ in our case). Following Eq. (3), imposing that the borehole temperature anomalies predicted by Eq. (1) for $t_{k}$ years ago at depth $z_{j}$ agree with the measured data leads to the linear system

$\mathbf{L} \boldsymbol{\tau}=\boldsymbol{m}$, where the column vector $\boldsymbol{\tau}=\left[\tau_{1}, \tau_{2}, \ldots, \tau_{N}, \tau_{\infty}\right]$ collects the unknown GST values, $\boldsymbol{m}$ is the column vector of detrended measured data and $\mathbf{L}$ is a matrix with $M \times(J+1)$ entries (see the Appendix). Each row in $\mathbf{L}$ (and entry in the vector $\boldsymbol{m}$ ), corresponds to a measured temperature in the well at present or at some time in the past. In this fashion, the GST reconstruction can be based not only on a single temperature profile but also on the variation in the temperature profile between the present and some years ago. To the best of our knowledge, this possibility, which enhances the robustness of the reconstruction, has never been exploited before in the literature. Given the detrended measures $\boldsymbol{m}$, we must compute the vector $\tau$ solving the linear system Eq. (4). However it is well known that the inverse problem for the heat Eq. (1) is severely ill-posed and thus directly solving the linear system Eq. (4) would lead to a computed GST that would be highly oscillating and very far from the true physical values for $\boldsymbol{\tau}$. It is then necessary to introduce a regularization process by modifying the original problem (Eq. 4), in order to obtain an approximation that is well posed and less sensitive to errors in the right-hand side of Eq. (4). Classical regularization techniques include the truncated singular value decomposition (TSVD) and the Tikhonov regularization in standard form (Hansen, 1998), applied in Beltrami and Bourlon (2004) and Liu and Zhang (2014), respectively. In this paper, we propose the use of the generalized Tikhonov regularization, where the damping term is measured by a proper seminorm. In practice, instead of dealing with the linear system Eq. (4), we solve the minimization problem

$\|\mathbf{L} \boldsymbol{\tau}-\boldsymbol{m}\|+\alpha\|\mathbf{R} \boldsymbol{\tau}\|$,

where $\alpha>0$ is the regularization parameter and $\mathbf{R}$ is the regularization matrix. The use of a regularization matrix $\mathbf{R}$ for this application is a novelty, although several other regularization smoothing parameters were already used (i.e. Shen et al., 1992; Rath and Mottaghy, 2007). If $\mathbf{R}$ is simply the identity matrix, then the problem (Eq. 5) reduces to the standard Tikhonov method used in Liu and Zhang (2014). When $\alpha$ is large the restored GST is very smooth but the differences between the measured data and the temperatures in the well that would be computed by Eq. (4) from the recovered GST are large. On the contrary, when $\alpha$ is too small the data fitting is good but the GST becomes highly oscillating due to 


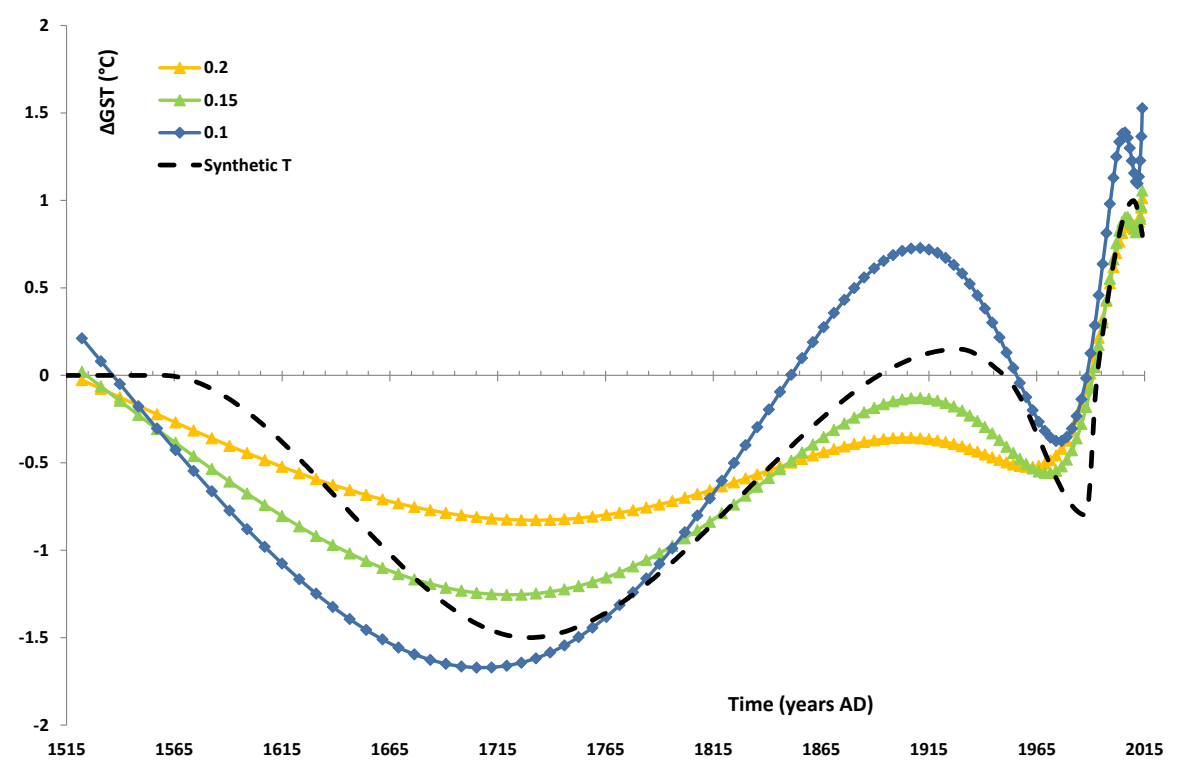

Figure 4. Synthetic data for the present time. It is remarkable that by also varying the $\alpha$ value by $33 \%$, the reconstructed GST does not vary significantly. Legend: 0.1: blue line; 0.15: green line; 0.2: orange line.

the ill-posedness. A good trade-off is not trivial and several strategies can be explored for estimating an optimal value of $\alpha$ : as an example, the generalized cross validation (Golub et al., 1979) often provides good results.

A common choice for $\mathbf{R}$ is a finite difference discretization of a differential operator (Hansen, 1998). In this paper, we consider a standard discretization of the Laplacian so that the constant and linear components of the solution are not damped in the Tikhonov regularization, Eq. (5), while we have a penalization of high oscillations. The details of the chosen regularization and of the GST inversion employed are described in the Appendix.

\subsection{Validation on synthetic data}

In order to validate our GST inversion method we have generated a synthetic data set as follows. An ideal GST was chosen (dashed curve in Fig. 4) and Eq. (1) was solved using a finite difference method with a spatial grid spacing of $1 \mathrm{~m}$. Homogeneous Neumann boundary conditions were imposed at the well bottom and the ideal GST as Dirichlet data at $z=0$, thus obtaining synthetic data for the measurements of temperature in the well. The computed temperatures were saved for the depth at which the real thermometers in SSB are located (see Sect. 3.1), for the present time, as well as for 1, 2 and 3 years before present. We then used the generated data as input to the inversion algorithm described in the previous section and compared the reconstructed GST with the ideal one used to generate the synthetic data.

In the first experiment we fed our inversion algorithms only with the synthetic data for the present time. The value of $\alpha$ that best fits the exact GST is $\alpha=0.15$, but in Fig. 4 one can see that also varying this value by $33 \%$ the reconstructed GST does not vary significantly.

Next we also fed the inversion algorithm with the synthetic data for the past years. First, the inversion is expected to be more accurate since the algorithm can average not only the temperature at a given depth but also the variation in the temperature in the last years at that depth. Moreover, the algorithm should also be more robust since it relies on a larger data set. Both these effects can be appreciated in Fig. 5, where it can be seen that the inversion in the last 50 years is more accurate than the inversion of Fig. 4 and that a wider variation in the value of $\alpha$ is possible without affecting the quality of the reconstruction very much.

\section{Results}

\section{Permafrost temperature, thermal properties and GST reconstruction}

The SSB stratigraphy is characterized by four different facies of dolostone (Fig. 6): a massive dolostone (from grey to pinky grey) comprises more than $90 \%$ of the profile; three other facies (white dolostone, black stratified limestone, brownish dolostone) are thin intercalations (maximum $3.5 \mathrm{~m}$ of thickness and located mainly in the first $42 \mathrm{~m}$ ). In particular facies $d$ was not analysed for thermal analyses because it is very limited and does not have any lateral continuity.

The mean annual thermal profiles of the last three years (2013, 2014 and 2015) show a negative gradient between 


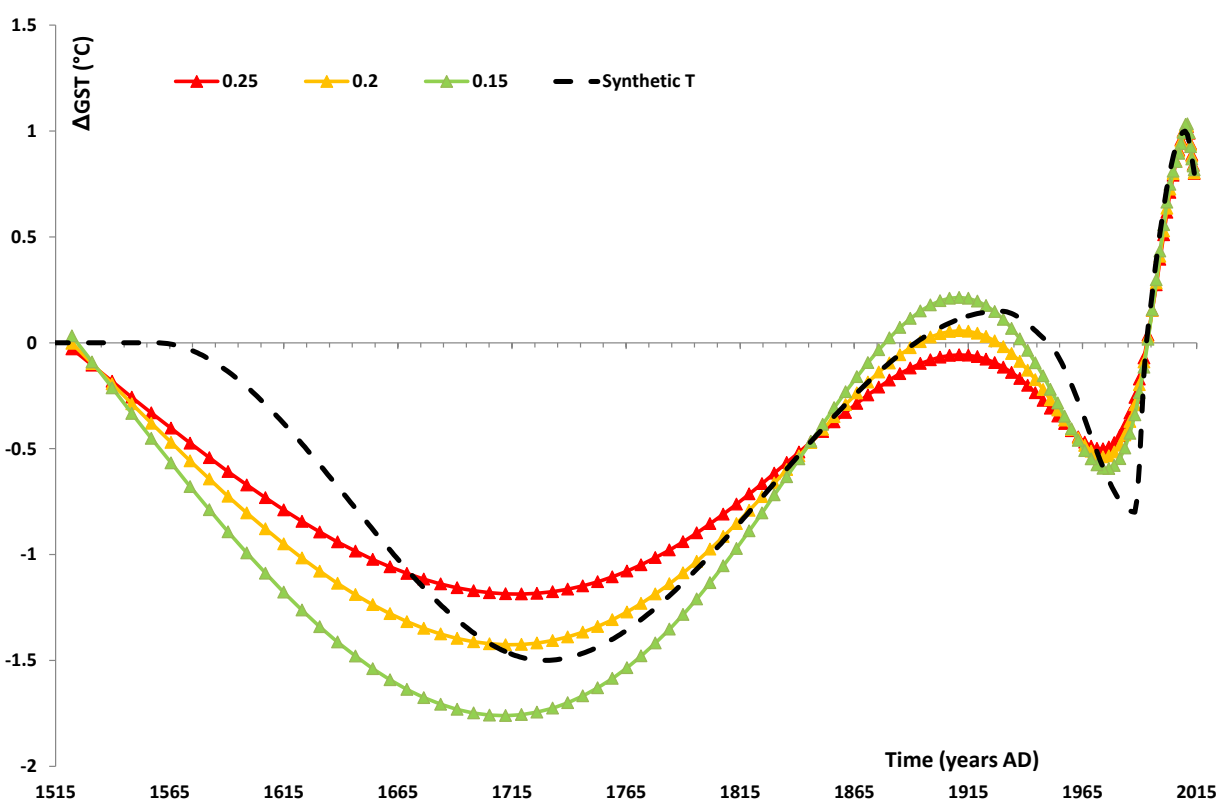

Figure 5. Synthetic data for three past years (2013, 2014 and 2015). It can be seen that the inversion in the last 50 years is more accurate than the inversion of Fig. 4. Legend: 0.15: green line; 0.2: orange line; 0.25: red line.

Table 1. Thermal gradients $\left({ }^{\circ} \mathrm{Cm}^{-1}\right)$ in 2013,2014 and 2015 in the different depth intervals of the profile below the zero annual amplitude that is approximately at $20 \mathrm{~m}$ of depth.

\begin{tabular}{rrrrrrrr}
\hline & $\begin{array}{r}20-60 \mathrm{~m} \\
\left({ }^{\circ} \mathrm{Cm}^{-1}\right)\end{array}$ & $\begin{array}{r}60-105 \mathrm{~m} \\
\left({ }^{\circ} \mathrm{Cm}^{-1}\right)\end{array}$ & $\begin{array}{r}105-125 \mathrm{~m} \\
\left({ }^{\circ} \mathrm{Cm}^{-1}\right)\end{array}$ & $\begin{array}{r}125-205 \mathrm{~m} \\
\left({ }^{\circ} \mathrm{Cm}^{-1}\right)\end{array}$ & $\begin{array}{r}205-215 \mathrm{~m} \\
\left({ }^{\circ} \mathrm{Cm}^{-1}\right)\end{array}$ & $\begin{array}{r}215-235 \mathrm{~m} \\
\left({ }^{\circ} \mathrm{Cm}^{-1}\right)\end{array}$ & $\begin{array}{r}60-235 \mathrm{~m} \\
\left({ }^{\circ} \mathrm{Cm}^{-1}\right)\end{array}$ \\
\hline 2013 & 0.0088 & -0.0072 & -0.0048 & -0.0075 & -0.0128 & -0.0058 & -0.0072 \\
2014 & & & -0.0046 & -0.0074 & -0.0128 & -0.0056 & \\
2015 & 0.0086 & -0.0077 & -0.0045 & -0.0073 & -0.0128 & -0.0055 & -0.0072 \\
\hline
\end{tabular}

Table 2. Thermal properties of the three different facies occurring in SSB measured in the laboratory at three different steps of temperature $\left(0 ;-1\right.$ and $\left.-2{ }^{\circ} \mathrm{C}\right)$.

\begin{tabular}{lrrrr}
\hline & $\begin{array}{r}\text { Density } \\
\left(\mathrm{g} \mathrm{cm}^{-3}\right)\end{array}$ & $\begin{array}{r}\text { Diffusivity } \\
\left(10^{-6} \mathrm{~m}^{2} \mathrm{~s}^{-1}\right)\end{array}$ & $\begin{array}{r}\text { Heat capacity } \\
\left(\mathrm{Jg}^{-1} \mathrm{~K}^{-1}\right)\end{array}$ & $\begin{array}{r}\text { Conductivity } \\
\left(\mathrm{W} \mathrm{m}^{-1} \mathrm{~K}^{-1}\right)\end{array}$ \\
\hline Facies a & & & & \\
\hline $0{ }^{\circ} \mathrm{C}$ & & 2.2 & 0.7 & 4.5 \\
$-1{ }^{\circ} \mathrm{C}$ & 2.7 & 2.1 & 0.8 & 4.4 \\
$-3{ }^{\circ} \mathrm{C}$ & & 2.1 & 0.8 & 4.4 \\
\hline Facies b & & & & \\
\hline $0^{\circ} \mathrm{C}$ & & 2.8 & 0.8 & 6.2 \\
$-1{ }^{\circ} \mathrm{C}$ & 2.8 & 2.8 & 0.8 & 6.2 \\
$-3{ }^{\circ} \mathrm{C}$ & & 2.8 & 0.8 & 6.2 \\
\hline Facies c & & & & \\
\hline $0{ }^{\circ} \mathrm{C}$ & & 2.0 & 0.8 & 4.0 \\
$-1{ }^{\circ} \mathrm{C}$ & 2.7 & 1.9 & 0.8 & 3.9 \\
$-3{ }^{\circ} \mathrm{C}$ & & 1.9 & 0.8 & 4.0 \\
\hline
\end{tabular}

$20 \mathrm{~m}$ (a depth corresponding approximately to the depth of zero annual amplitude, ZAA) and $60 \mathrm{~m}$ that does not vary $\left(-0.8^{\circ} \mathrm{C} / 100 \mathrm{~m}\right.$ in all three years). At greater depth, the gradient is positive with slightly different slopes between 60 105; 105-125; 125-205; 205-215 and 215-235 (Fig. 7 and Table 1).

Table 2 shows the thermal properties of the three main stratigraphic facies encountered in the borehole. Facies a and $\mathrm{c}$ show similar density and thermal properties while facies $\mathrm{b}$ has higher density and higher conductivity. All facies have heat capacity values that increase with a decrease in temperature. In facies a, this behaviour also occurs for thermal conductivity and diffusivity values. In contrast, facies $b$ and c show a reversed bell shape behaviour, with the minimum value recorded at $-1{ }^{\circ} \mathrm{C}$ and an absolute maximum at $-3^{\circ} \mathrm{C}$. Therefore, from a thermal point of view, only facies $b$ is different. Moreover, at depths below the level of zero annual amplitude, this facies occurs only at depths of 34.5 and $90 \mathrm{~m}$ with a negligible thickness ( 2 and $1 \mathrm{~m}$ respectively) and at 142.5 and $205 \mathrm{~m}$ where it reaches $3-3.5 \mathrm{~m}$ in thickness. 


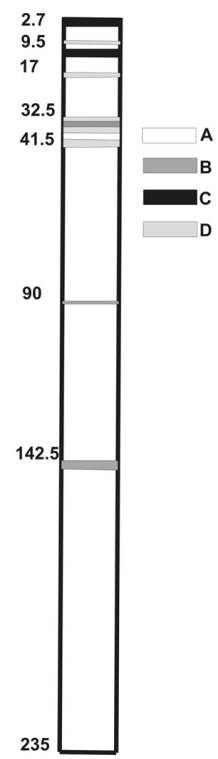

Figure 6. Share Stelvio Borehole (SSB) stratigraphy. Legend: (a) facies a (massive dolostone from grey to pinky grey); (b) facies b (white dolostone); (c) facies c (black stratified limestone); (d) facies d (light brown dolostone).

Clearly, the thermal influence of this facies is negligible; indeed, the gradient between 60 and $235 \mathrm{~m}$ is approximately the same as that between 60 and $105 \mathrm{~m}$ and between 125 and $205 \mathrm{~m}$. The effects of the different thermal diffusivities measured in the different facies of the SSB are also illustrated in Fig. 8 where is possible to notice that the difference of temperature a posteriori between a model with a constant diffusivity equal to the average value of facies a between 0 and $-1{ }^{\circ} \mathrm{C}$ (red dots) and the model with the different diffusivities for each different facies layer (blue dots) is absolutely negligible $\left(<0.02^{\circ} \mathrm{C}\right)$ at all the depths, with the exception of the uppermost $20 \mathrm{~m}$, where the difference is higher but still very low $\left(0.06^{\circ} \mathrm{C}\right)$.

According to the model proposed in Sect. 3, we found the best fitting with the thermal profiles (Fig. 7) using a heat flow of $70 \mathrm{~mW} \mathrm{~m}^{-2}$ (Della Vedova et al., 1995), a thermal diffusivity value equal to the mean between the value obtained for 0 and $-1{ }^{\circ} \mathrm{C}$ for facies a, which is more widespread in the borehole, and an $\alpha$ value of 0.95 as shown in Fig. 9.

The linear system (4) was assembled including the detrended data measured at SSB in $2015\left(T_{j}=0\right)$, in 2014 $\left(T_{j}=1\right)$ and $2013\left(T_{j}=2\right)$, at the 13 depths listed in Sect. 3.1, resulting in 39 equations. The anomalies of the GST reconstruction obtained with respect to the reference period between 1880 and 1960 has been computed using the value of $\alpha=0.95$ for the regularization parameter (Fig. 10).

\section{Discussion}

\subsection{GST and current air temperatures}

In permafrost environments, snow cover can influence GST variability in both space and time (e.g. Zhang, 2005; Schmidt et al., 2009; Morse et al., 2012; Rodder and Kneisel, 2012; Schmid et al., 2012; Guglielmin et al., 2014). This is especially the case for alpine areas where topography influences both the re-distribution of the snow by wind drift and actual snow cover evolution (e.g. melting date and duration). Nevertheless, GST and air temperature are well correlated $\left(R^{2}=0.8027\right)$ and present a very similar pattern over the last 15 years with only a slight warming (Fig. 11). This relatively slight effect of snow at this site is probably due to the high wind velocities during winter that, on average, prevent buildup of a thick snowpack. Figure 12 illustrates the temporal variability in snow cover on the GST. In general, the highest $\left(> \pm 5^{\circ} \mathrm{C}\right)$ differences between mean daily GST and mean daily air temperature occur when there are large drops of air temperature during the winter. Sometimes, large differences also occur when there are large drops of air temperature during the summer where there is little or no snow cover because of high solar radiation that heats the ground surface. Correlation is even better between monthly mean air temperature, mean annual air temperature (MAAT) and mean annual GST (MAGST) $\left(R^{2}=0.8712\right.$ for this latter). This agrees with the results of Zhang and Stamnes (1998), who found that in a flat area in northern Alaska, changes in seasonal snow cover had a smaller effect than MAAT on the ground thermal regime.

\subsection{GST fluctuations between 1950 and today}

Our reconstruction after the cold GST anomaly, between AD 1906 and 1941, shows a slightly positive peak (ca. $0.1{ }^{\circ} \mathrm{C}$ ) in 1930 and afterwards a very unstable period with a first sharp decrease in temperature until 1989 (between -0.2 and $-0.6^{\circ} \mathrm{C}$ ) and a second even sharper increase, reaching the uppermost GST anomaly value of the last 500 years (around $1{ }^{\circ} \mathrm{C}$ ) in 2011 .

On a regional scale, the Stelvio data can be compared with the MAAT obtained for the Alps by Christiansen and Ljungqvist (2011) (Fig. 10) and Trachsel et al. (2010). The maximum of the slight temperature increase during the first half of the 20th century in the Stelvio data (1930) falls exactly in the middle of the relative warming period between 1925 and 1935 in the Alps found by Trachsel et al. (2010) and is in good agreement with the date (1928) indicated by Christiansen and Ljungqvist (2011). Later, the sharp GST anomaly decrease was delayed in the Stelvio data (1989) with respect to the 1950-1965 period found by Trachsel et al. (2010) and 1965-1975 period found by Christiansen and Ljungqvist (2011). Finally, the most recent increase in temperature culminated in the Alps in 1994 (Christiansen and 


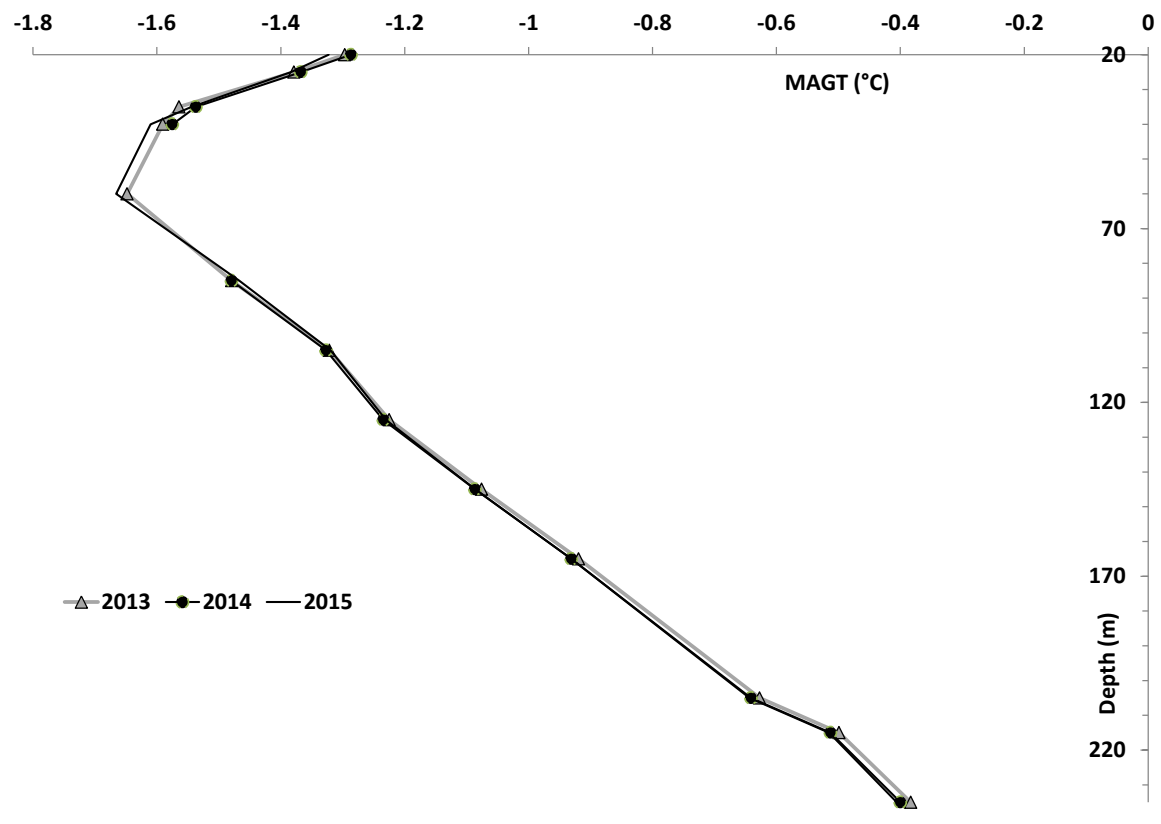

Figure 7. SSB mean annual ground temperature profiles in 2013, 2014 and 2015.

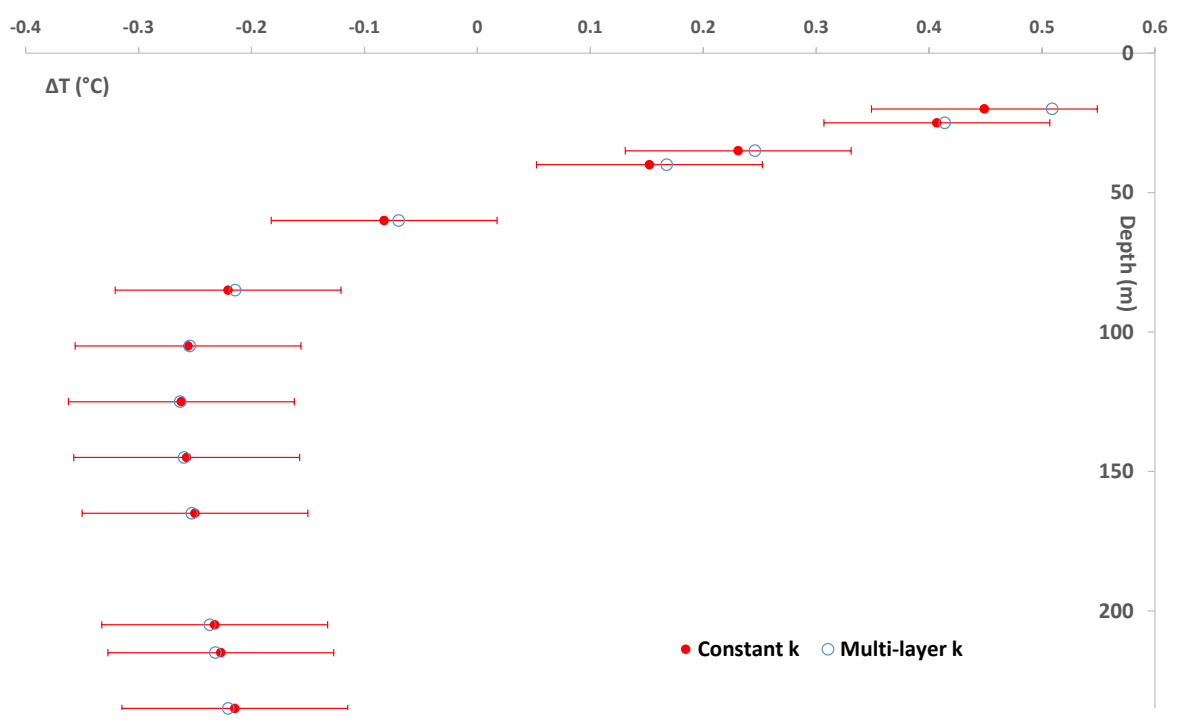

Figure 8. Effects of different thermal diffusivity used in the model. The temperature profiles a posteriori of 2015 obtained in the case of a constant thermal diffusivity value of the more widespread facies a (red dots) and in the case with multi-layer thermal diffusivities following the different facies according to Fig. 6 (blue dots). The bars indicate the variations in the measured temperature in the same year.

Ljungqvist, 2011), while in the Stelvio data it culminated in 2011.

\subsection{The Little Ice Age (LIA)}

The Stelvio reconstruction shows a long period of negative anomaly between AD 1560 and 1860 with colder conditions $(<-2 \cdot \mathrm{SD})$ between 1683 and AD 1784 and with a peak at $-1.5^{\circ} \mathrm{C}$ around $\mathrm{AD} 1730$. This period of negative anomaly falls within this well-known cooling period (LIA). It is recognized in several kinds of proxy data although there are differences in both magnitude and timing across the world. According to Neukom et al. (2014), synchronous cold temperature anomalies occurred at a decadal scale in both hemispheres between AD 1594 and 1677. They also found two phases of extreme cold temperature in the Northern Hemisphere with the first between AD 1570 and 1720 and the second between 1810 and 1855. Syntheses of the LIA in the Eu- 


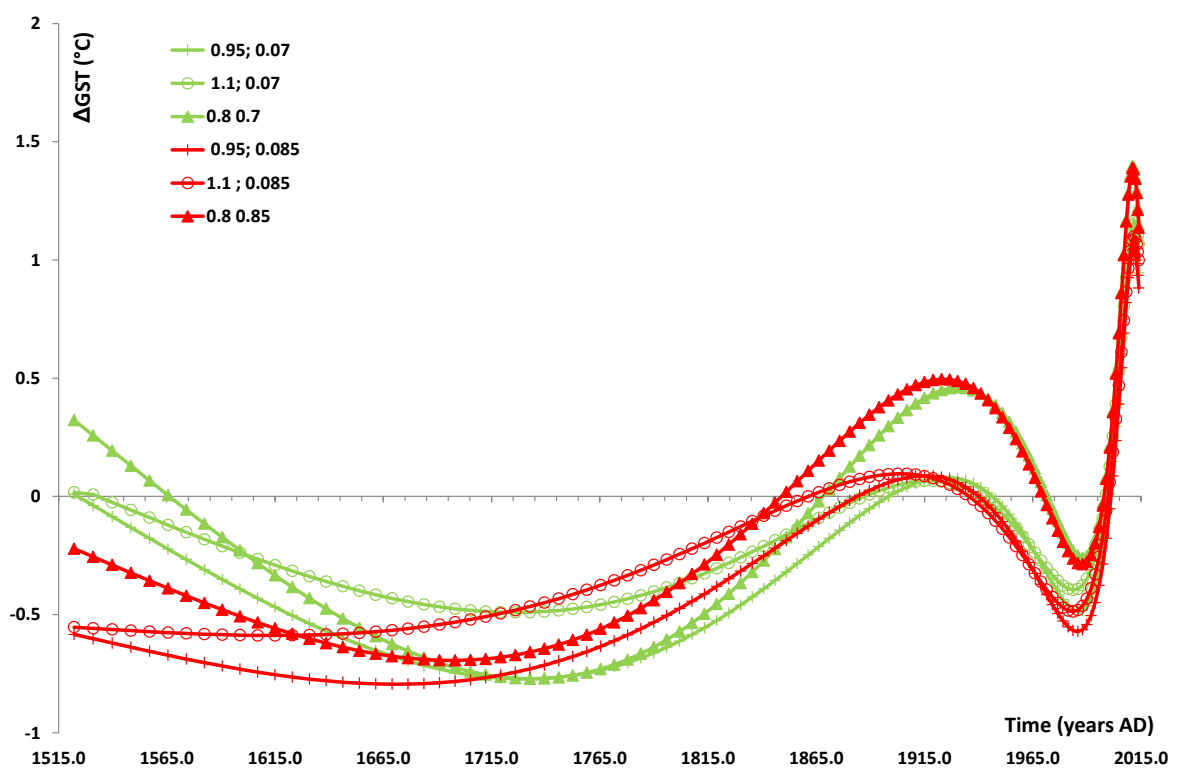

Figure 9. Example of different GST histories with different $\alpha$ values with the extreme of heat flow values known for the region. Legend: green lines are obtained with a heat flow of $70 \mathrm{~mW} \mathrm{~m}^{-2}$ while red lines are obtained with $85 \mathrm{~mW} \mathrm{~m}^{-2}$. The different symbols indicate different $\alpha$ values (0.95: solid line; 1.1: empty dots; 0.8: triangles).

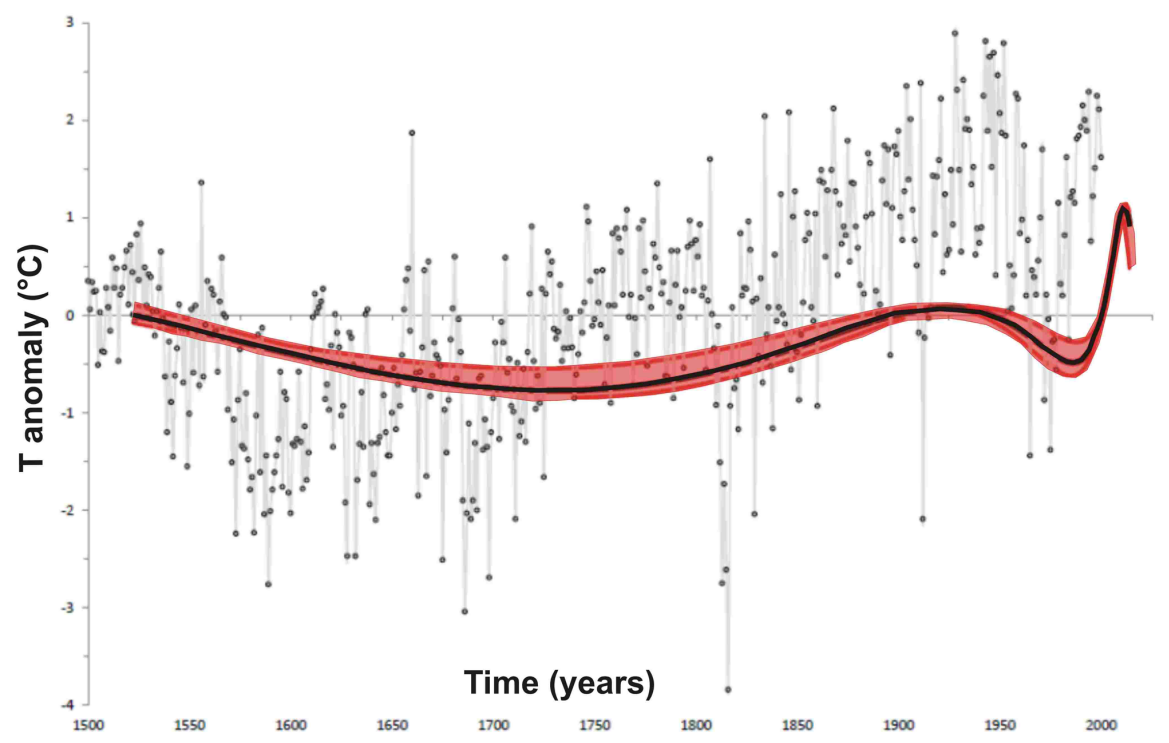

Figure 10. Comparison among the anomaly of the mean annual GST reconstructed by the SSB (black thick line), its uncertainty range (red shaded) and the MAAT anomaly reconstructed for the European Alps by Christiansen and Ljungqvist (2011) (grey line with dots; data available online at https://www.ncdc.noaa.gov/paleo/study/12355, last access: 19 June 2012), both in respect to the same reference period (1880-1960).

ropean Alps have been presented by Trachsel et al. (2012) and Christiansen and Ljungqvist (2011). Considering the common colder periods in these two Alpine syntheses, the LIA has three main negative peaks at AD 1570-1600, 16851700 and $1790-1820$.
The LIA period has also been characterized by a widespread worldwide glacier advance, although the comparison between glacial evidences and temperature fluctuations is problematic because glaciers respond with different timescales (mainly depending on their size) and also reflect the precipitation regime, which is even more variable 


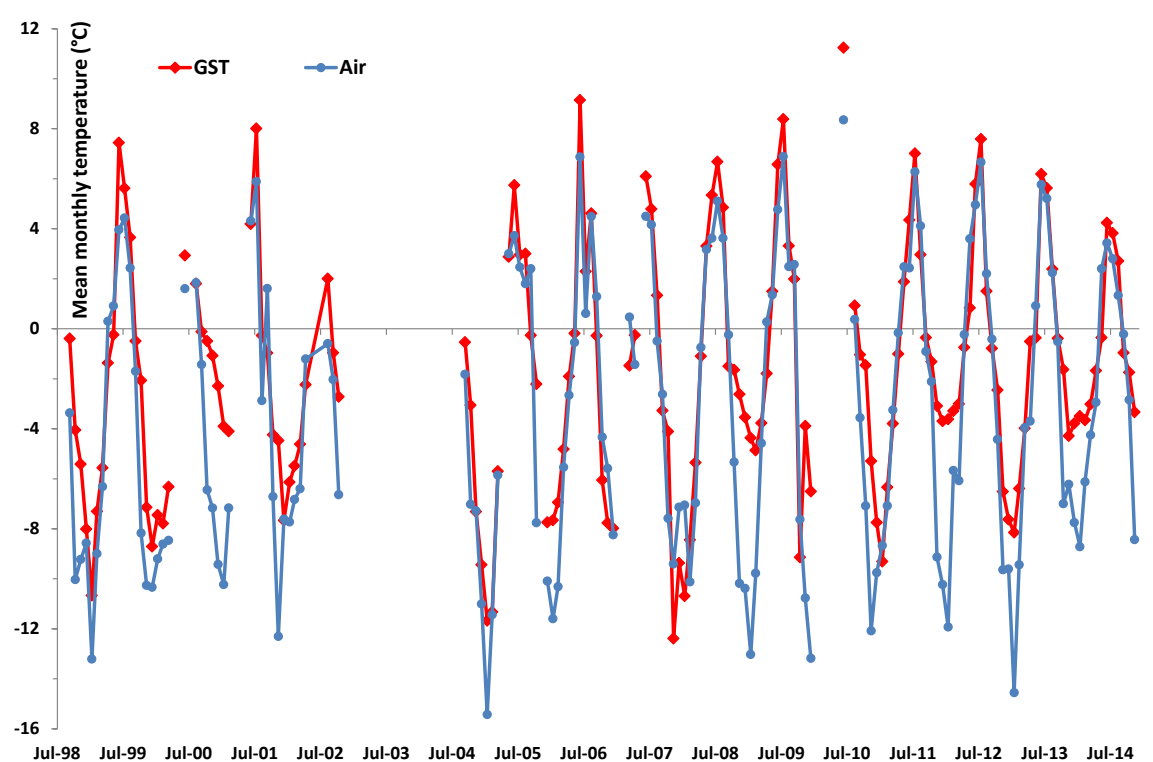

Figure 11. Trend of monthly mean of GST (red line) and air temperature (blue line) at SSB since 1998.

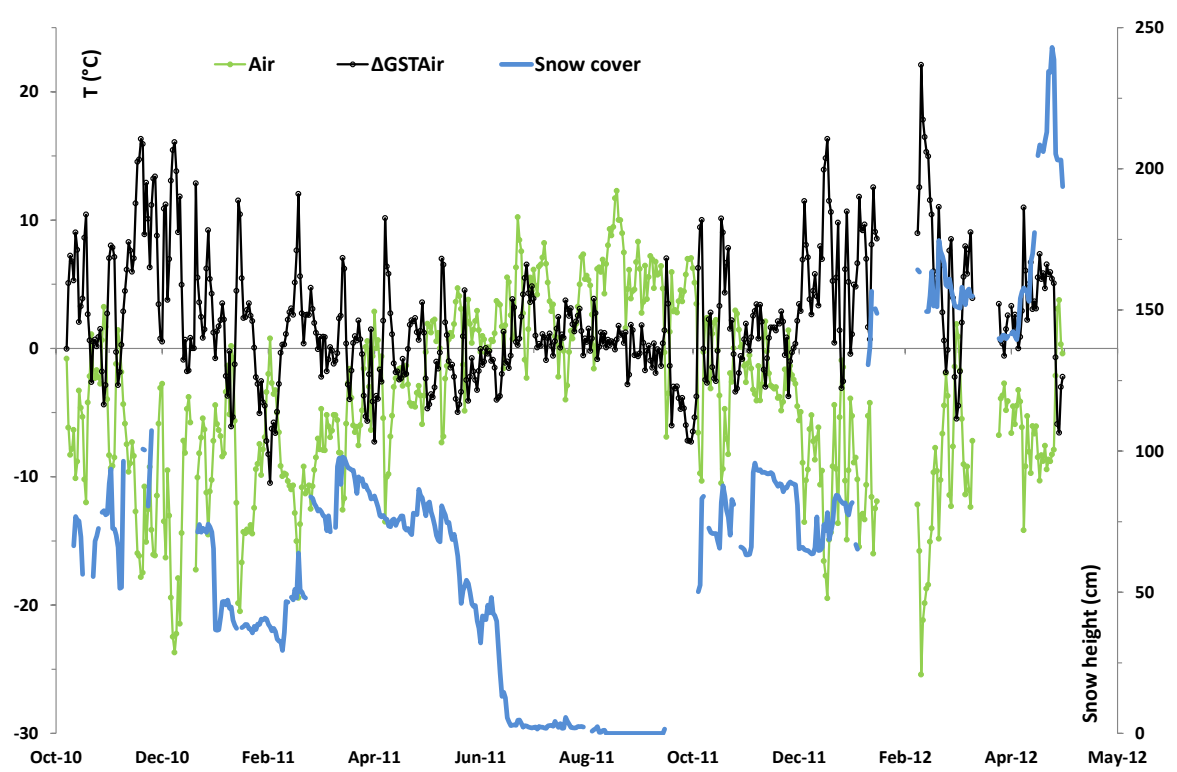

Figure 12. Effect of the snow cover at SSB. The winter 2010/11 is representative of the average conditions of the snow cover at SSB while the following season 2011/12 was the snowiest of the whole monitoring period. The difference between the daily mean GST and air temperature ( $\triangle$ GSTair; black line) shows greater values during the greater drop in air temperature (green line) during the winter due to the insulating effect of the snow cover (blue line), whereas the few episodes of high $\Delta$ GSTair in the summer may be due to the solar radiation that warms the ground surface.

in space and time. According to Holzhauser et al. (2005), the LIA advance of the main Swiss glaciers has three peaks around $\mathrm{AD} 1350,1640$ and $1820-1850$ respectively with the two later phases almost synchronous, also in the Eastern Alps (Nicolussi and Patzelt, 2000).
Close to the location of the SSB, the maximum LIA advance was diachronous. Nearby glaciers show a maximum LIA advance in AD 1580 (Trafoi Valley glacier; Cardassi, 1995), around AD 1770 (Solda glacier; Arzuffi and Pelfini, 2001) and in AD 1600 (La Mare glacier; Carturan et al., 2014). 


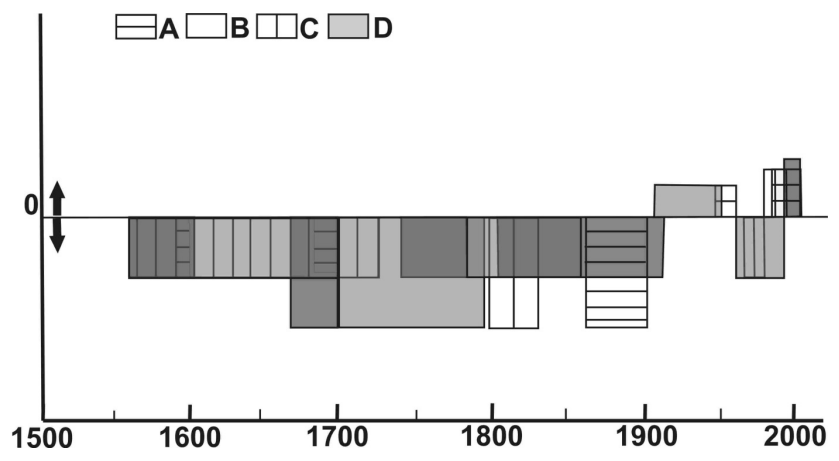

Figure 13. Main climatic events enhanced by anomalies of MAAT through different proxies in all of Europe: A (modified from Luterbacher et al., 2004); central Europe: B (re-elaborated from Dobrovolný et al., 2010); Alps: C (modified from the same data of Fig. 5; Christiansen and Ljungqvist, 2011) and SSB: D (this paper).

The borehole area was presumably over-capped by the Vedretta Piana glacier until 1868. Due to the geomorphological position (on a watershed divide) the possible glacier should have been very thin and possibly cold based, as already stressed by Guglielmin et al. (2001). However, considering Fig. 10, the glacier should have been present in the borehole area with a buffering effect only between AD 1711 and 1834, with a peak at 1760, when the difference between the GST anomaly and the MAAT anomaly was maximum. This peak is pretty similar to the peak of the LIA in the Solda glacier (AD 1770) but not to the peak in the Trafoi glacier (AD 1580); this could be related to Vedretta Piana having a more similar glacier size and aspect (NE-N) to the Solda glacier than to the Trafoi glacier, although this latter is the closest to the Vedretta Piana.

\subsection{Other permafrost borehole temperature reconstructions}

Several deep Alaskan boreholes have been used to demonstrate the 20th century warming (e.g. Lachenbruch and Marshall, 1986; Lachenbruch et al., 1988) but only a few studies in Europe illustrate GST reconstructions that span a time period greater than 100-150 years (e.g. Isaksen et al., 2001; Guglielmin, 2004). In North America, only Chouinard et al. (2007) show a GST pattern of the last 300 years in the context of the permafrost of northern Québec. There, after the LIA (AD 1500-1800), an almost constant and marked warming of ca. $1.4^{\circ} \mathrm{C}$ until 1940 was found, followed by a cooling episode $\left(\approx 0.4^{\circ} \mathrm{C}\right)$ which lasted $40-50$ years, and finally a sharp $\approx 1.7^{\circ} \mathrm{C}$ warming over the past 15 years.

There is a some similarity between the Stelvio reconstruction and the pattern of Canadian permafrost GST reported by Chouinard et al. (2013) after the LIA. Indeed, at our site there was also an almost simultaneous but greater cooling $\left(0.9^{\circ} \mathrm{C}\right)$ in the period between 1941 and 1989, followed by a sharp warming of ca. $1.7^{\circ} \mathrm{C}$. Conversely, GST reconstructions can be obtained with different models and it is interesting to compare our data with, for example, the PMIP3-CMIP5 simulations that include the effect of aerosol forcing by GarcíaGarcía et al. (2016): there, in the last 500 years, the GST shows a cold anomaly (LIA) between 1582 and 1840, with the most negative peaks between 1798 and 1840, slightly delayed with respect to our data.

\section{Conclusions}

The general climatic pattern of the last 500 years recorded by this mountain permafrost borehole is similar to the majority of other studies in the European Alps and central Europe. The main difference concerns post LIA events. In fact, the different multi-disciplinary proxies considered (see Fig. 13) do not indicate cooling between 1940 and 1989, with the exceptions of the shorter and less severe cooling found for the Alps. It is also relevant to stress that the rapid and abrupt GST warming (more than $0.8^{\circ} \mathrm{C}$ per decade) recorded between 1990 and 2011 in the Stelvio borehole data is similar to the warming recorded in permafrost in northern Québec. This warming trend is of the same magnitude as the increase in MAAT between 1990 and 2000 in central Europe (Dobrovolný et al., 2010), and is approximately double that found for the MAAT in the Alps and for Europe as a whole (Luterbacher et al., 2004).

The Stelvio borehole GST reconstruction also allows one to estimate changes in the Vedretta Piana glacier. This glacier presumably buried the site of the Stelvio borehole with an ice thickness sufficient to exert a significant buffering effect upon the ground thermal regime between AD 1711 and 1834 . This was a time when the difference between the Stelvio GST anomaly and the MAAT anomaly was greatest.

Data availability. After publication the borehole temperature data cited here will be uploaded to the GTn-P database at http:// gtnpdatabase.org/boreholes/view/894) (Guglielmin, 2018). 
Appendix A: Details of the regularization and inversion technique

The temperature anomaly in the borehole at time $t$ and at depth $z$ is modelled by the solution of the heat equation

$$
\frac{\partial A}{\partial t}-\frac{\partial}{\partial z}\left(\kappa \frac{\partial A}{\partial z}\right)=0
$$

for the domain $(t, z) \in\left(-t_{\max }, 0\right) \times\left(0, z_{\max }\right)$. If the boundary data $A(t, 0)$ are piecewise constant, then the solution of the direct problem for Eq. (1) can be found explicitly (see Carlsaw and Jaeger, 1959). In fact, the anomaly observed in the borehole $t$ years ago, originating from a GST that has been constant except for an increase of $\delta^{\circ} \mathrm{C}$ between $t_{2}$ and $t_{1}$ years ago is

$A(t, z)=\delta\left[\operatorname{erfc}\left(\frac{z}{\sqrt{4 \kappa\left(t_{2}-t\right)}}\right)-\operatorname{erfc}\left(\frac{z}{\sqrt{4 \kappa\left(t_{1}-t\right)}}\right)\right]$.

The above formula of course makes sense only for $t<t_{1}$ and the value $t=0$ corresponds to present time. For the purpose of reconstructing the GST history, it is customary to approximate it with a piecewise constant function (see Fig. 3):

$\operatorname{GST}(t)=\left\{\begin{array}{ll}\tau_{k}, & t \in\left[-t_{k},-t_{k-1}\right], \\ \tau_{\infty}, & t<t_{N}\end{array}\right.$,

where $t_{k}$, for $k=1, \ldots, N$, is the sequence of times in the past for which we want to compute the value of the GST, and the $\tau_{k}$ 's are the unknown values to be computed. The prediction of model (1) for the borehole temperature $t$ years ago, originating from the GST (Eq. A2) is

$$
\begin{aligned}
& A(z, t)=\tau_{1} \varphi\left(z, t_{1}-t\right)+\sum_{k=1}^{N} \tau_{k} \\
& {\left[\varphi\left(z, t_{k+1}-t\right)-\varphi\left(z, t_{k}-t\right)\right]-\tau_{\infty} \varphi\left(z, t_{N}-t\right),}
\end{aligned}
$$

where $\varphi(z, t)=\operatorname{erfc}\left(\frac{z}{\sqrt{4 k t}}\right)$. Note that, once the sequence $t_{k}$ is chosen, the relation between the borehole temperature at depth $z_{j}$ predicted by the model and the unknown values $\tau_{k}$ of the GST anomaly is thus linear. The matrix $\mathbf{L}$ of the linear system (Eq. 4) in the main text is thus

$\mathbf{L}_{j, 1}=\varphi\left(Z_{j}, t_{1}-T_{j}\right)$

$\mathbf{L}_{j, k}=\varphi\left(Z_{j}, t_{k+1}-T_{j}\right)-\varphi\left(Z_{j}, t_{k}-T_{j}\right)$

$\mathbf{L}_{j, N+1}=\varphi\left(Z_{j}, t_{N}-T_{j}\right)$.

We point out that each row of the matrix $\mathbf{L}$ can have a different value of $T_{j}$, so that the GST reconstruction can be based not only on a single temperature profile, but also on the variation in the temperature profile between the present and some years ago. Further, it is not needed that the reconstruction times $t_{k}$ are equally spaced in the past.

Given the detrended measures $\boldsymbol{m}$, we must compute the vector $\tau$ solving the linear system Eq. (4). Note that the inverse problem for the heat Eq. (1) is well known to be severely ill-posed; the matrix $\mathbf{L}$ is strongly ill-conditioned and its singular values decay exponentially to zero, with related singular vectors largely intersecting the subspace of high frequencies (Serra-Capizzano, 2004). Therefore, since the right-hand-side $\boldsymbol{m}$ is affected by error measurements, directly solving the linear system Eq. (4) would lead to a computed GST that would be highly oscillating and very far from the true physical values for $\boldsymbol{\tau}$. It is then necessary to introduce a regularization process by modifying the original problem (4) in order to obtain an approximation that is well posed and less sensitive to errors in the right-hand side of Eq. (4). The Tikhonov regularization usually provides better restorations than the truncated SVD because it is characterized by a smooth transition in the filtering of the frequencies and the smoothness of the transition can be somehow chosen by manipulating the regularization parameter of the method (Hansen, 1998). In this paper, we thus propose the use of the generalized Tikhonov regularization, where the damping term is measured by a proper seminorm. In practice, instead of dealing with the linear system (4), we solve the minimization problem

$\|\mathbf{L} \boldsymbol{\tau}-\boldsymbol{m}\|+\alpha\|\mathbf{R} \boldsymbol{\tau}\|$,

where $\alpha>0$ is the regularization parameter and $\mathbf{R}$ is the regularization matrix. The presence of the matrix $\mathbf{R}$ in Eq. (5) allows us to impose some a priori information on the true solution. Indeed, when minimizing Eq. (5), the components of the solution belonging to $\operatorname{ker}(\mathbf{R})=\{\boldsymbol{x} s \cdot \boldsymbol{t} \cdot \mathbf{R} \boldsymbol{x}=\mathbf{0}\}$ are perfectly reconstructed. In fact, if a vector $\boldsymbol{x}$ belongs to $\operatorname{ker}(\mathbf{R})$ then $\|\mathbf{R} \boldsymbol{x}\|=0$ and hence the penalization term disappears in the minimization problem (5) and consequently the data are perfectly fitted. Note that in order to guarantee the uniqueness of the solution (5), the condition $\operatorname{ker}(\mathbf{L}) \cap \operatorname{ker}(\mathbf{R})=\mathbf{0}$ has to hold.

In this paper, we use as regularizer a standard discretization of the Laplacian

$\mathbf{R}=\frac{1}{4}\left[\begin{array}{rrrrrr}-1 & 2 & -1 & & & \\ & -1 & 2 & -1 & & \\ & & \ddots & \ddots & \ddots & \\ & & & -1 & 2 & -1\end{array}\right]$

of size $(N-2) \times N$ and hence the constant and linear components of the solution are not damped in the Tikhonov regularization (5). 
Appendix B: Comparison of 1-D and higher-dimensional models for SSB

In order to ascertain the effect of the terrain geometry we conducted a number of forward simulations with the model (1) using the synthetic GST shown in Fig. 4 (dashed line) and already employed for the sensitivity analysis as boundary data.

First we computed the solution of the one-dimensional model Eq. (1). Next we computed the solution of the corresponding three-dimensional model in a computational domain of $400 \times 400 \mathrm{~m}$ centred around SSB and $500 \mathrm{~m}$ deep, the top surface of which was obtained from a DEM (with a resolution of $10 \mathrm{~m}$ ). Such a domain was discretized with the Gmsh mesh generator software and the heat equation was solved using linear Lagrange finite elements in space and backward Euler in time. The mesh was refined until numerical convergence was observed and in Fig. B1 we present the results for a mesh with 1.3 million tetrahedra. The numerical simulations were performed with the HPC cluster of the Dipartimento di Matematica of the Università di Torino.
Figure B1 compares the temperature anomalies that each of the models would predict at SSB at present time. The red dots are the predicted well anomalies at the depth of the thermometers at SSB. One can see that the predictions of the twodimensional model with flat terrain (blue line) almost coincide with those of the one-dimensional one. Furthermore, the two-dimensional model applied to the section with the steeper sides (the SSW-NNE one, orange line) gives rise to predictions that are within the instrumental error $\left( \pm 0.1{ }^{\circ} \mathrm{C}\right)$, whereas the N-S section (red line), which has a flatter terrain, gives rise to predictions that are quite close to those of the one-dimensional model. The predictions of the 3-D model (dashed black line) are very close to the 2-D flat and the 2-D N-S (with difference always $<0.03{ }^{\circ} \mathrm{C}$ ) models.

Finally, let us remark that for the forward model, a numerical 3-D simulation takes hours to complete on $16 \mathrm{com}$ puting nodes of our HPC cluster. Using a numerical multidimensional simulator in the inverse problem would of course require computing the forward model several times and would thus take a lot longer than the few seconds in which our proposed method can compute the reconstructed GST depicted in Fig. 10.

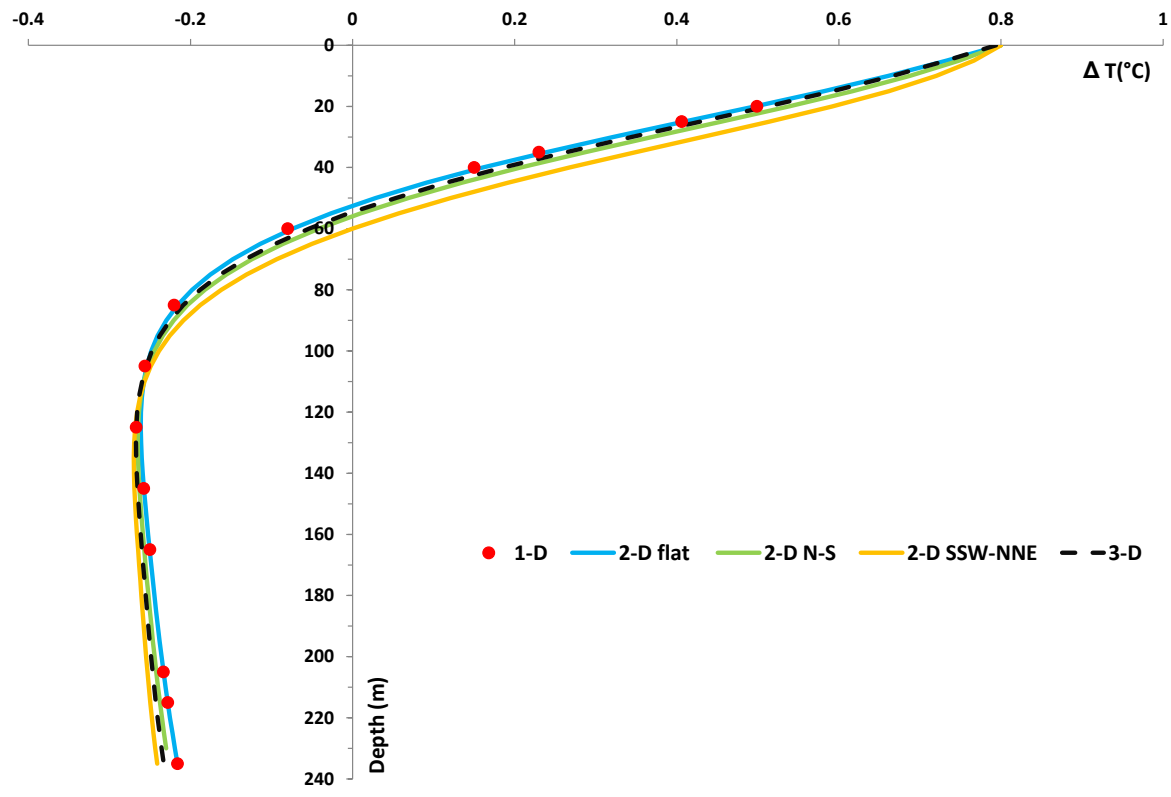

Figure B1. Comparison of predictions of the forward model for the same GST and different geometrical setups. Legend: 1-D: red dots; 2-D flat terrain: blue line; 2-D N-S: green line; 2-D SSW-NNE: orange line; 3-D: dashed black line (see the Appendix for the details). 
Competing interests. The authors declare that they have no conflict of interest.

Acknowledgements. The SSB was drilled and equipped thanks to the project "Share Stelvio" managed by EvK2-CNR and funded by Regione Lombardia. The research was also funded through the PRIN 2008 project "Permafrost e piccoli ghiacciai alpini come elementi chiave della gestione delle risorse idriche in relazione al Cambiamento Climatico" led by Claudio Smiraglia. Special thanks to the Stelvio National Park, SIFAS and Umberto Capitani for the permission and the logistical support. We also want to thank Hugh M. French for revision and English editing of a previous version of the paper.

Edited by: Volker Rath

Reviewed by: Volker Rath and one anonymous referee

\section{References}

Arzuffi, L. and Pelfini, M.: I testimoni dei cambiamenti climatici, Neve e Valanghe, 43, 44-53, 2001.

ASTM: Standard Test Method for Thermal Diffusivity by the Flash Method, ASTM International, West Conshohocken, PA, available at: www.astm.org (last access: 28 March 2011), https://doi.org/10.1520/E1461-07, 2003.

Auer, I., Böhm, R., Jurkovic, A., Lipa, W., Orlik, A., Potzmann, R., Schöner, W., Ungersböck, M., Matulla, C., Briffa, K., Jones, P., Efthymiadis, D., Brunetti, M., Nanni, T., Maugeri, M., Mercalli, L., Mestre, O., Moisselin, J.M., Begert, M., Müller-Westmeier, G., Kveton, V., Bochnicek, O., Stastny, P., Lapin, M., Szalai, S., Szentimrey, T., Cegnar, T., Dolinar, M., Gajic-Capka, M., Zaninovic, K., Majstoroviv, Z., and Nieplova, E.: HISTALP-historical instrumental climatological surface time series of the Greater Alpine Region, Int. J. Climatol., 27, 17-46, 2007.

Barbante, C., Schwikowski, M., Döring, T., Gäggeler, H. W., Schotterer, U., Tobler, L., Van de Velde, K., Ferrari, C., Cozzi, G., Turetta, A., Rosman, K., Bolshov, M., Capodaglio, G., Cescon, P., and Boutron, C.: Historical record of European emissions of trace elements to the atmosphere since the 1650s from alpine snow/ice cores drilled near Monte Rosa, Environ. Sci. Technol., 38, 4085-4090, 2004.

Beltrami, H. and Bourlon, E.: Ground warming patterns in the northern hemisphere during the last five centuries, Earth Planet. Sc. Lett., 227, 169-177, 2004.

Böhm, R., Auer, I., Brunetti, M., Maugeri, M., Nanni, T., and Schöner, W.: Regional temperature variability in the European Alps: 1760-1998 from homogenized instrumental time series, Int. J. Climatol., 21, 1779-1801, 2001.

Büntgen, U., Frank, D. C., Nievergelt, D., and Esper, J.: Summer temperature variations in the European Alps, A.D. 755-2004, J. Climate, 19, 5606-5623, 2006.

Cardassi, S. P.: Geologia del Quaternario e geomorfologia della Valle di Trafoi, Master's Thesis, University of Milan, 1995.

Carlsaw, H. S. and Jaeger, J. C.: Conduction of Heat in Solids, Oxford Univ. Press, New York, 510 p., 1959.

Carturan, L., Baroni, C., Carton, A., Cazorzi, F., Dalla Fontana, G., Delpero, C., Salvatore, M. C., Seppi, R., and Zanoner, T.: Recon- structing fluctuations of La Mare Glacier (Eastern Italian Alps) in the Late Holocene: new evidence for a Little Ice Age maximum around 1600 ad., Geogr. Ann. A, 96, 287-306, 2014.

Cermak, V., Balling, N., Della Vedova, B., Lucazeau, F., Pasquale, V., Pellis, G., Schulz, R., and Verdoya, M.: Heat-flow data (Italy), in: A Continent Revealed: The European Geotraverse Database, edited by: Blundell, D., Freeman, R., and Mueller, S., Cambridge Univ. Press, Cambridge, 49-57, 1992.

Chouinard, C., Fortier, R., and Mareschal, J. C.: Recent climate variations in the subarctic inferred from three borehole temperature profiles in northern Quebec, Canada, Earth Planet. Sc. Lett., 263, 355-369, 2007.

Christiansen, B. and Ljungqvist, F. C. Reconstruction of the extratropical $\mathrm{NH}$ mean temperature over the last millennium with a method that preserves low-frequency variability, J. Climate, 24, 6013-6034, 2011

Clauser, C. and Huenges, E.: Thermal conductivity of rocks and minerals, in: Rock Physics and Phase Relations. A Handbook of Physical Constants, edited by: Ahrens, T. J., AGU Reference Shelf 3, American Geophysical Union, Washington, 105-126, 1995.

Cook, B. I., Bonan, G. B., Levis, S., and Epstein, H. E.: The thermoinsulation effect of snow cover within a climate model, Clim. Dynam., 31, 107-124, 2008.

Corona, C., Guiot, J., Edouard, J. L., Chalié, F., Büntgen, U., Nola, P., and Urbinati, C.: Millennium-long summer temperature variations in the European Alps as reconstructed from tree rings, Clim. Past, 6, 379-400, https://doi.org/10.5194/cp-6-379-2010, 2010.

Della Vedova, B., Lucazeau, F., Pasquale, V., Pellis, G., and Verdoya, M.: Heat flow in the tectonic provinces crossed by the southern segment of the European Geotraverse, Tectonophysics, 244, 57-74, 1995.

Dobrovolný, P., Moberg, A., Brázdil, R., Pfister, C., Glaser, R., Wilson, R., van Engelen, A., Limanówka, D., Kiss, A., Halícková, M., Macková, J., Riemann, D., Luterbacher, J., and Böhm, R.: Monthly, seasonal and annual temperature reconstructions for Central Europe derived from documentary evidence and instrumental records since AD 1500, Clim. Change, 101, 69-107, 2010.

García-García, A., Cuesta-Valero, F. J., Beltrami, H., and Smerdon, J. E.: Simulation of air and ground temperatures in PMIP3/CMIP5 last millennium simulations: implications for climate reconstructions from borehole temperature profiles, Environ. Res. Lett., 11, 044022, https://doi.org/10.1088/17489326/11/4/044022, 2016.

Golub, G. H., Heath, M., and Wahba, G.: Generalized CrossValidation as a Method for Choosing a Good Ridge Parameter, Technometrics, 21, 215-223, 1979.

Gruber, S., King, L., Kohl, T., Herz, T., Haeberli, W., and Hoelzle, M.: Interpretation of geothermal profiles perturbed by topography: the Alpine permafrost boreholes at Stockhorn Plateau, Switzerland, Permafrost Periglac., 15, 349-357, 2004.

Guglielmin, M.: Observations on permafrost ground thermal regimes from Antarctica and the Italian Alps, and their relevance to global climate change, Global Planet. Change, 40, 159-167, 2004.

Guglielmin, M.: Global Terrestrial Network on Permafrost (GTN-P) Database, available at: http://gtnpdatabase.org/boreholes/view/ 894, last access: 28 May 2018. 
Guglielmin, M., Cannone, N., and Dramis, F.: Permafrost-glacial evolution during the Holocene in the Italian Central Alps, Permafrost Periglac., 12, 111-124, 2001.

Guglielmin, M., Worland, M. R., Baio, F., and Convey, P.: Permafrost and snow monitoring at Rothera Point (Adelaide Island, Maritime Antarctica): Implications for rock weathering in cryotic conditions, Geomorphology, 225, 47-56, 2014.

Hansen, P.: Rank-Deficient and Discrete Ill-Posed Problems, Society for Industrial and Applied Mathematics, SIAM, Philadelphia, PA, USA, 1998.

Harris, C., Haeberli, W., Vonder Muhll, D., and King, L.: Permafrost monitoring in the high mountains of Europe: the PACE Project in its global context, Permafrost Periglac., 12, 3-11, 2001.

Harris, C., Vonder Mühll, D., Isaksen, K., Haeberli, W., Sollid, J. L., King, L., Holmlund, P., Dramis, F., Guglielmin, M., and Palacios, D.: Warming permafrost in European mountains, Global Planet. Change, 39, 215-225, 2003.

Hilbich, C., Hauck, C., Hoelzle, M., Scherler, M., Schudel, L., Völksch, I., Vonder Mühll, D., and Mäusbacher, R.: Monitoring mountain permafrost evolution using electrical resistivity tomography: a 7-year study of seasonal, annual, and long-term variations at Schilthorn, Swiss Alps, J. Geophys. Res., 113, F01S90, https://doi.org/10.1029/2007JF000799, 2008.

Holzhauser, H., Magny, M., and Zumbühl, H. J.: Glacier and lakelevel variations in west-central Europe over the last 3500 years, Holocene, 15, 789-801, 2005.

Huang, S., Pollack, H. N., and Shen, P. Y.: Temperature trends over the last five centuries reconstructed from borehole temperatures, Nature, 403, 756-758, 2000.

IPCC: Summary for policymakers, in: Climate Change 2013: The Physical Science Basis, Contribution of Working Group I to the Fifth Assessment Report of the Intergovernmental Panel on Climate Change, edited by: Stocker, T. F., Qin, D., Plattner, G. K., Tignor, M. S. K., Allen, J., Boschung, A., Nauels, Y., Xia, Y., Bex, V., and Midgley, P. M., Cambridge University Press: Cambridge, UK and New York, NY, 2013.

Isaksen, K., Vonder Muhll, D., Gubler, H., Kohl, T., and Sollid, J. L.: Ground surface-temperature reconstruction based on data from a deep borehole in permafrost at Janssonhaugen, Svalbard, Ann. Glaciol., 31, 287-294, 2001.

Lachenbruch, A. H. and Marshall, B. V.: Changing climate: geothermal evidence from permafrost in the Alaskan Arctic, Science, 234, 689-696, 1986.

Lachenbruch, A. H., Cladouhos, T. T., and Saltus, R. W.: Permafrost temperature and the changing climate. "Permafrost", 5th International Permafrost Conference Proceedings, Tapir Publishers, Trondheim, Norway, 3, 9-17, 1988.

Larocque-Tobler, I., Grosjean, M., Heiri, O., Trachsel, M., and Kamenik, C.: Thousand years of climate change reconstructed from chironomid subfossils preserved in varved lake Silvaplana, Engadine, Switzerland, Quaternary Sci. Rew., 29, 1940-1949, 2010.

Lewis, T. J. and Wang, K.: Influence of terrain on bedrock temperatures, Palaeogeogr. Palaeocl., 98, 87-100, 1992.

Ling, F. and Zhang, T. J.: Sensitivity of ground thermal regime and surface energy fluxes to tundra snow density in northern Alaska, Cold Reg. Sci. Technol., 44, 121-130, 2006.

Liu, J. and Zhang, T.: Fundamental solution method for reconstructing past climate change from borehole temperature gradients, Cold Reg. Sci. Technol., 102, 32-40, 2014.
Luterbacher, J., Dietrich, D., Xoplaki, E., Grosjean, M., and Wanner, H.: European seasonal and annual temperature variability, trends, and extremes since 1500, Science, 303, 1499-1503, 2004.

Morse, P. D., Burn, C. R., and Kokelj, S. V.: Influence of snow on near-surface ground temperatures in upland and alluvial environments of the outer Mackenzie Delta, N.W.T. Can. J. Earth Sci., 49, 895-913, 2012.

Mottaghy, D. and Rath, V.: Latent heat effects in subsurface heat transport modelling and their impact on palaeotemperature reconstructions, Geophys. J. Int., 164, 236-245, 2006.

Neukom, R., Gergis, J., Karoly, D. J., Wanner, H., Curran, M., Elbert, J., González-Rouco, F., Linsley, B. K., Moy, A. M., Mundo, I., Raible, C. C., Steig, E. J., van Ommen, T., Vance, T., Villalba, R., Zinke, J., and Frank, D.: Inter-hemispheric temperature variability over the past millennium, Nat. Clim. Change, 4, 362-367, 2014.

Nicolussi, K. and Patzelt, G.: Discovery of early Holocene wood and peat on the forefield of the Pasterze Glacier, Eastern Alps, Austria, Holocene, 10, 191-199, 2000.

Rath, V. and Mottaghy, D.: Smooth inversion for ground surface temperature histories: estimating the optimum regularization parameter by generalised cross-validation, Geophys. J. Int., 171, 1440-1448, 2007.

Rath, V., González Rouco, J. F., and Goosse, H.: Impact of postglacial warming on borehole reconstructions of last millennium temperatures, Clim. Past, 8, 1059-1066, https://doi.org/10.5194/cp-8-1059-2012, 2012.

Rodder, T. and Kneisel, C.: Influence of snow cover and grain size on the ground thermal regime in the discontinuous permafrost zone, Swiss Alps, Geomorphology, 175-176, 176-189, 2012.

Safanda, J. and Rajver, D.: Signature of the last ice age in the present subsurface temperatures in the Czech Republic and Slovenia, Global Planet. Change, 29, 241-257, 2001.

Schmid, M.-O., Gubler, S., Fiddes, J., and Gruber, S.: Inferring snowpack ripening and melt-out from distributed measurements of near-surface ground temperatures, The Cryosphere, 6, 11271139, https://doi.org/10.5194/tc-6-1127-2012, 2012.

Schmidt, S., Weber, B., and Winiger, M.: Analyses of seasonal snow disappearance in an alpine valley from micro- to mesoscale (Loetschental, Switzerland), Hydrol. Process., 23, 10411051, 2009.

Serra-Capizzano, S.: A note on the antireflective boundary conditions and fast deblurring models, SIAM Journal on Scientific Computing, 25-4, 1307-1325, 2004.

Shen, P. Y., Wang, K. H., and Beltrami Mareschal, J. C.: A comparative study of inverse methods for estimating climatic history from borehole temperature data, Palaeogeogr. Palaeocl., 98, 113-127, 1992.

Trachsel, M., Grosjean, M., Larocque-Tobler, I., Schwikowski, M., Blass, A., and Sturm, M.: Quantitative summer temperature reconstruction derived from a combined biogenic Si and chironomid record from varved sediments of Lake Silvaplana (southeastern Swiss Alps) back to AD 1177, Quaternary Sci. Rev., 29, 2719-2730, 2010.

Trachsel, M., Kamenik, C., Grosjean, M., McCarroll, D., Moberg, A., Brázdil, R., Büntgen, U., Dobrovolný, P., Esper, J., Frank, D. C., Friedrich, M., Glaser, R., Larocque-Tobler, I., Nicolussi, K., and Riemann, D.: Multi-archive summer temperature recon- 
struction for the European Alps, AD 1053-1996, Quaternary Sci. Rev., 46, 66-79, 2012.

Zhang, T.: Influence of the seasonal snow cover on the ground thermal regime: An overview, Rev. Geophys., 43, RG4002, https://doi.org/10.1029/2004RG000157, 2005.
Zhang, T. and Stamnes, K.: Impact of climatic factors on the active layer and permafrost at Barrow, Alaska, Permafrost Periglac., 9, 229-246, 1998. 